(2) Open Access Full Text Article

REVIEW

\title{
Assessing the Safety and Efficacy of Trifarotene in the Treatment of Acne Vulgaris
}

\author{
Caitlin M Brumfiel ${ }^{\prime}$ \\ Meera $\mathrm{H}$ Patel $^{2}$ \\ Katheryn A Bell (D) \\ Michael A Cardis ${ }^{3}$ \\ 'Georgetown University School of \\ Medicine, Washington, DC, USA; \\ ${ }^{2}$ Creighton University School of \\ Medicine, Phoenix Regional Campus, \\ Phoenix, AZ, USA; ${ }^{3}$ MedStar Washington \\ Hospital Center/Georgetown University \\ Hospital Department of Dermatology, \\ Washington, DC, USA
}

\begin{abstract}
Acne vulgaris is a common skin condition of the face and trunk that negatively impacts quality of life. Trifarotene is a new first-in-class fourth-generation topical retinoid that has been uniquely studied in the treatment of both facial and truncal acne. Through selective agonism of retinoic acid receptor (RAR)-gamma, the most predominant RAR isotype in the epidermis, trifarotene exerts more targeted, skin-specific effects than earlier generation retinoids. This narrative review summarizes all currently available literature regarding the use of trifarotene in acne vulgaris. We focus on efficacy, safety, and tolerability data and highlight quality of life outcomes and patient-reported satisfaction. Future clinical trials and the clinical applicability of this novel medication in the treatment of acne are also discussed.
\end{abstract}

Keywords: acne vulgaris, trifarotene, retinoid, randomized controlled trials

\section{Introduction}

Acne vulgaris, or acne, is a common cutaneous disorder that manifests as comedones, papules, pustules, and/or nodules on the face, neck, and trunk. Epidemiologic studies indicate acne affects approximately $9.4 \%$ of the global population, ranking it as the eighth most prevalent disease worldwide. ${ }^{1}$ Up to $85 \%$ of adolescents experience acne and while often mistakenly perceived as a disease limited to teenagers, many adults are affected as well. ${ }^{2,3}$ The psychosocial effects of acne are well documented and include negative impacts on selfperception, social functioning, and mental health. ${ }^{4-6}$

The pathogenesis of acne involves follicular hyperkeratinization with comedo formation and inflammation of the pilosebaceous unit, which is composed of the hair follicle and accompanying sebaceous gland. Acne lesions are thought to form via a complex dynamic of androgen-mediated sebaceous gland stimulation, microbial dysbiosis, and innate and adaptive immunoreactivity. ${ }^{7}$ Genetic predisposition and environmental factors such as stress and diet also likely influence the development of acne in susceptible individuals. ${ }^{8}$

The therapeutic paradigm for acne involves interventions with topical medications in mild-to-moderate disease with the addition of systemic medications as severity increases. ${ }^{9}$ Each therapy targets one or more pathophysiologic aspects of lesion formation. ${ }^{10}$ Topical retinoids, azelaic acid, and isotretinoin target follicular hyperproliferation and abnormal desquamation. Oral contraceptives, spironolactone, isotretinoin, and clascoterone diminish androgen-associated sebum production. Benzoyl peroxide, antibiotics, azelaic acid, and to a lesser extent, retinoids,
Correspondence: Caitlin M Brumfiel

Georgetown University School of

Medicine, 3900 Reservoir Road,

Washington, DC, 20007, USA

$\mathrm{Tel}+1$ 5I3-260-3948

Email cmb373@georgetown.edu 
mitigate Cutibacterium acnes proliferation. Topical retinoids, isotretinoin, and antibiotics exert antiinflammatory properties. Given their targeted action in multiple pathways of disease activity, topical retinoids are critical to the acne treatment armamentarium.

Retinoids are synthetic derivatives of vitamin A and have been first-line therapies for both inflammatory and noninflammatory acne vulgaris for decades. ${ }^{11}$ They are efficacious as monotherapy and exhibit dose-dependent effects, yielding better responses with higher medication strengths. ${ }^{12}$ Retinoids also enhance penetration of other topical agents and act synergistically with various medications, such as antimicrobials, for improved efficacy. ${ }^{12}$ Mechanistically, retinoids mediate their effects by binding to the intranuclear retinoic acid receptor (RAR) or retinoic $\mathrm{X}$ receptor (RXR), each of which has three major isotypes (alpha, beta, and gamma). Receptor binding leads to downstream gene transcription and regulation of cellular differentiation, proliferation, and apoptosis. ${ }^{13}$

Four generations of retinoids have been developed, each with differing molecular properties and RAR subtype specificity. All-trans retinoic acid (ATRA) or tretinoin (firstgeneration), adapalene and tazarotene (third-generation), and trifarotene (fourth-generation) are all topical formulations approved by the US Food and Drug Administration (FDA) for the treatment of acne vulgaris. Trifarotene, approved in October $2019,{ }^{14}$ is the only topical retinoid that binds selectively to RAR-gamma, which is the most predominant isoform in the epidermis. ${ }^{13}$ It is the first new topical retinoid approved by the FDA in over 20 years and the only that has been studied in both facial and truncal acne. In this review, we summarize all published data regarding the safety and efficacy of trifarotene in the treatment of acne vulgaris (Figure 1).

\section{Methods}

A literature review was conducted using PubMed and Ovid Medline databases to identify eligible articles. The terms

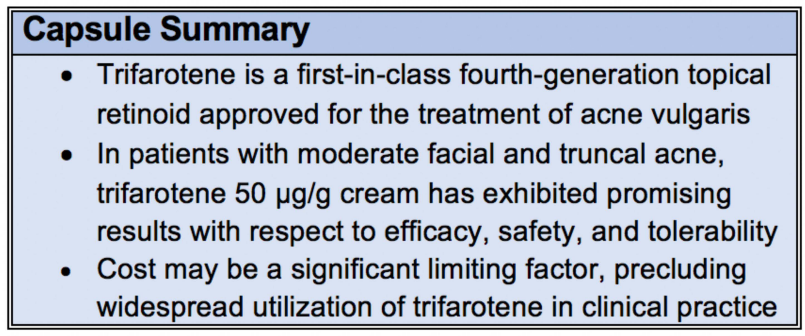

Figure I Capsule summary. "trifarotene" and "CD5789" were searched and all articles published through April 10, 2021 were reviewed and crosschecked independently by two reviewers. All Englishlanguage primary literature regarding the use of trifarotene in acne vulgaris and pertaining to pharmacology, efficacy, safety, and/or quality of life was included. Reference lists of included articles were further screened for additional eligible articles. Each article was critically reviewed and the following variables were extracted: study design, endpoints, baseline characteristics of patients, efficacy data, and safety data. Due to the limited number of available articles, this review is structured in narrative format.

A search was also performed to confirm inclusion of all published clinical trial data in our review as well as to report on upcoming or currently ongoing trials investigating the use of trifarotene in acne vulgaris. "Acne vulgaris" was searched in the "Condition or disease" section, and "trifarotene" and "CD5789" were searched in the "Other Terms" section of clinicaltrials.gov. All result entries were reviewed independently for inclusion by two reviewers.

\section{Pharmacologic Features of Trifarotene \\ Mechanism of Action and Downstream Biologic Effects}

Trifarotene was developed following detailed characterization of the RAR-gamma ligand binding domain by Thoreau et al. ${ }^{13}$ This drug exhibits high selectivity and potency for RAR-gamma, exerting minimal activity on RAR-alpha and RAR-beta (65-fold and 16-fold lower, respectively), and no activity on RXR. ${ }^{15}$ Activation of specific receptor subtypes influences unique downstream biologic and clinical effects. ${ }^{16}$ RAR binding leads to receptor dimerization and subsequent activation of retinoic acid receptor response element (RARE) genes. Topical retinoids, including trifarotene, generally confer comedolytic, anti-inflammatory, and antipigmenting properties in the skin, thus contributing to their therapeutic benefit in acne. Murine model data demonstrated that trifarotene yields superior comedolytic effects at lower concentrations than other retinoids such as tazarotene and ATRA, and also exerts better antipigmenting effects than adapalene. ${ }^{15}$

Large-scale translational transcriptomics identified that trifarotene modulates known processes associated with retinoid use, such as epidermal differentiation, proliferation, and response to stress. ${ }^{15}$ Interestingly, gene expression studies also indicated that trifarotene affects novel 
pathways not previously associated with other retinoids, including:

1. Cell adhesion: trifarotene downregulates dystonin, weakening hemidesmosomes and intercellular adhesions, which allows keratinocyte migration and comedolysis;

2. Skin hydration: through upregulation of aquaporin 3 and peptidyl arginine deiminase 1, trifarotene influences skin barrier function and enhances cutaneous hydration; and

3. Proteolysis: trifarotene downregulates matrix metalloproteinases, which are proteins that degrade collagen and elastin, thus effectively promoting antiaging benefits in the skin. ${ }^{17}$

\section{Pharmacokinetics}

In preclinical study, Aubert et al demonstrated trifarotene is highly metabolically stable in ex vivo human keratinocytes ( $>24$ hours) but is rapidly metabolized by hepatic microsomes (half-life $<5$ minutes), resulting in high cutaneous activity while maintaining low systemic concentrations. $^{15}$ Other available retinoids have much longer hepatic microsomal half-lives, such as tazarotenic acid (57 minutes) and adapalene ( $>60$ minutes). The rapid elimination of trifarotene by the liver is important when applying the medication to large body surface areas, as in truncal acne, allowing possible safety issues associated with systemic absorption to be minimized. ${ }^{15,16}$

Two clinical studies examining pharmacokinetics and safety in adult (18-34 years) and pediatric (10-17 years) patients with moderate-to-severe acne vulgaris demonstrated that when applied daily under maximal use conditions, plasma concentrations of trifarotene were only quantifiable in $37 \%$ of adults and $18 \%$ of children who applied the $50 \mu \mathrm{g} / \mathrm{g}$ formulation vs in $61 \%$ of adults and $69 \%$ of children who used $100 \mu \mathrm{g} / \mathrm{g}$. ${ }^{18}$ Systemic absorption was lower in the trifarotene $50 \mu \mathrm{g} / \mathrm{g}$ group (maximum concentration [Cmax] $5-10 \mathrm{pg} / \mathrm{mL}$ in adults; $7-9 \mathrm{pg} / \mathrm{mL}$ in children) than in the $100 \mu \mathrm{g} / \mathrm{g}$ group (Cmax $11 \pm 8 \mathrm{pg} / \mathrm{mL}$ in adults; $12 \pm 12 \mathrm{pg} / \mathrm{mL}$ in children). Overall, trifarotene had a short half-life ( 2 to 9 hours) and did not accumulate systemically despite repeat applications. Most adverse events (AEs) were cutaneous in nature (erythema or skin irritation) and were slightly more severe in the $100 \mu \mathrm{g} / \mathrm{g}$ group. No biochemical or hematologic abnormalities were identified. Results from this study confirmed that trifarotene is locally and systemically well tolerated as well as safe in both children and adults.

Given the intended patient population of trifarotene includes women of childbearing age and the retinoid drug class exhibits potential teratogenicity, ${ }^{19}$ a drug-drug interaction study was performed in healthy volunteers to examine the effects of trifarotene on oral contraceptives. ${ }^{18}$ Patients received a combination oral contraceptive of levonorgestrel $0.15 \mathrm{mg} /$ ethinyl estradiol $0.03 \mathrm{mg}$ (LNG/EE) and were coadministered trifarotene $100 \mu \mathrm{g} / \mathrm{g}$ (repeated daily applications to reach $2 \mathrm{~g}$ /day). Plasma levels of LNG/EE were unaffected by trifarotene and no clinically significant drug-drug interactions were identified, suggesting the intended effects of oral contraceptives are preserved despite concomitant trifarotene use.

\section{Pivotal Phase III Studies}

\section{I2-Week Clinical Trials (PERFECT I and PERFECT 2)}

PERFECT 1 and PERFECT 2 were the first large-scale, phase III studies to examine the efficacy and safety of trifarotene $50 \mu \mathrm{g} / \mathrm{g}$ cream in acne vulgaris. ${ }^{20}$ Both were identically designed, double-blinded, placebo-controlled, 12-week trials conducted from 2015-2017 at multiple international sites (United States, Canada, Europe, Russia). Patients $\geq 9$ years of age with moderate facial and truncal acne were included. Moderate was defined as Investigator Global Assessment (IGA) and Physician Global Assessment (PGA) score of 3. IGA and PGA were both 5 -point scales (from $0=$ clear to $4=$ severe) used to assess the face and trunk, respectively.

Efficacy was determined through three coprimary endpoints from baseline to week 12: success rate, as determined by IGA (percentage of patients who achieved an IGA face score of 0 [clear] or 1 [almost clear]) and $a \geq$ 2 -grade change from baseline, change in facial inflammatory lesion count, and change in facial noninflammatory lesion count. Secondary endpoints mirrored the 3 primary endpoints but involved the trunk and PGA.

In both trials combined, a total of 1214 patients were treated with trifarotene (612 patients in PERFECT 1 and 602 patients in PERFECT 2), and 1206 received vehicle (596 in PERFECT 1 and 610 in PERFECT 2). As summarized in Table 1, demographics and baseline disease characteristics were similar across treatment groups.

Regarding facial acne in the trifarotene group, rates of IGA success were $29.4 \%$ in PERFECT 1 and $42.3 \%$ in 
Table I Demographics and Baseline Disease Characteristics in Phase III Clinical Trials of Trifarotene in Acne Vulgaris

\begin{tabular}{|c|c|c|c|c|c|c|c|}
\hline & \multicolumn{3}{|c|}{ PERFECT $\mathrm{I}^{20}$} & \multicolumn{3}{|c|}{ PERFECT $2^{20}$} & \multirow{2}{*}{$\begin{array}{l}\text { 52-Week } \\
\text { Trifarotene }\end{array}$} \\
\hline & Trifarotene & Vehicle & Overall & Trifarotene & Vehicle & Overall & \\
\hline Number of patients & 612 & 596 & 1208 & 602 & 610 & 1212 & 444 \\
\hline Age, mean (SD) & $19.6 \pm 6.88$ & $19.3 \pm 5.89$ & $19.4 \pm 6.41$ & $19.6 \pm 6.2$ & $19.9 \pm 6.4$ & $19.7 \pm 6.3$ & $18.4 \pm 6.5$ \\
\hline \multicolumn{8}{|l|}{ Sex, n (\%) } \\
\hline Male & $307(50.2)$ & $272(45.6)$ & $579(47.9)$ & $245(40.7)$ & $272(44.6)$ & $517(42.7)$ & $227(5 I .1)$ \\
\hline Female & $305(49.8)$ & $324(54.4)$ & $629(52.1)$ & $357(59.3)$ & $338(55.4)$ & $695(57.3)$ & $217(48.9)$ \\
\hline \multicolumn{8}{|l|}{ Skin phototype $\mathrm{n}(\%)$} \\
\hline 1 & $31(5.1)$ & $34(5.7)$ & $65(5.4)$ & $36(6.0)$ & $37(6.1)$ & $73(6.0)$ & $13(2.9)$ \\
\hline ॥ & $197(32.2)$ & $182(30.5)$ & $379(31.4)$ & $274(45.5)$ & $249(40.8)$ & $523(43.2)$ & $182(41.0)$ \\
\hline III & $233(38.1)$ & $227(38.1)$ & $460(38.1)$ & $233(38.7)$ & $248(40.7)$ & $48 \mid(39.7)$ & $183(4 \mid .2)$ \\
\hline IV & $97(15.8)$ & $91(15.3)$ & $188(15.6)$ & $33(5.5)$ & $38(6.2)$ & $71(5.9)$ & $52(11.7)$ \\
\hline $\mathrm{V}$ & $43(7.0)$ & $48(8.1)$ & $91(7.5)$ & $14(2.3)$ & $19(3.1)$ & $33(2.7)$ & $7(1.6)$ \\
\hline VI & $11(1.8)$ & $14(2.3)$ & $25(2.1)$ & $12(2.0)$ & $19(3.1)$ & $31(2.6)$ & $\mathrm{I}(0.2)$ \\
\hline Missing & - & - & - & - & - & - & $6(1.4)$ \\
\hline \multicolumn{8}{|c|}{ Inflammatory lesion count, mean $( \pm S D)$} \\
\hline Face & $34.7 \pm 13.02$ & $34.8 \pm 13.612$ & $34.8 \pm 13.612$ & $36.1 \pm 12.47$ & $37.1 \pm 15.06$ & $36.6 \pm 13.84$ & 15.2 \\
\hline Trunk & $36.9 \pm 17.89$ & $35.6 \pm 16.70$ & $35.3 \pm 17.32$ & $39.0 \pm 16.16$ & $39.1 \pm 17.41$ & $39.1 \pm 16.80$ & $43.5 \pm 28.5$ \\
\hline \multicolumn{8}{|c|}{ Noninflammatory lesion count, mean $( \pm S D)$} \\
\hline Face & $54.0 \pm 28.55$ & $52.8 \pm 26.08$ & $53.4 \pm 27.35$ & $50.6 \pm 25.93$ & $51.2 \pm 25.75$ & $50.9 \pm 25.83$ & $58.5 \pm 37.0$ \\
\hline Trunk & $46.4 \pm 21.57$ & $47.5 \pm 21.94$ & $46.9 \pm 21.75$ & $46.1 \pm 20.17$ & $45.7 \pm 19.58$ & $45.9 \pm 19.87$ & $56.3 \pm 39.4$ \\
\hline
\end{tabular}

Abbreviations: $\mathrm{n}$, number; SD, standard deviation.

PERFECT 2 (vs $19.5 \%$ and $25.7 \%$ for vehicle; $\mathrm{p}<0.001$; Table 2A). Patients treated with trifarotene also achieved significantly greater reductions in facial inflammatory and noninflammatory lesion counts than those who received vehicle. Truncal acne responded similarly well to trifarotene, with PGA success rates of $35.7 \%$ in PERFECT 1 and $42.6 \%$ in PERFECT 2 (vs $25.0 \%$ and $29.9 \%$ for vehicle, $\mathrm{p}<0.001)$. Improvements in truncal inflammatory and non- inflammatory lesion counts were also significantly greater in the trifarotene group. Reductions in acne lesion counts occurred rapidly in both trials, with significant responses apparent as early as week 1 on the face and week 2 on the trunk.

Tolerability data was consistent with the known AE profile of topical retinoids and generally included transient, mild-to-moderate local irritation (erythema,

Table 2 Efficacy Results in Phase III Clinical Trials of Trifarotene in Acne Vulgaris

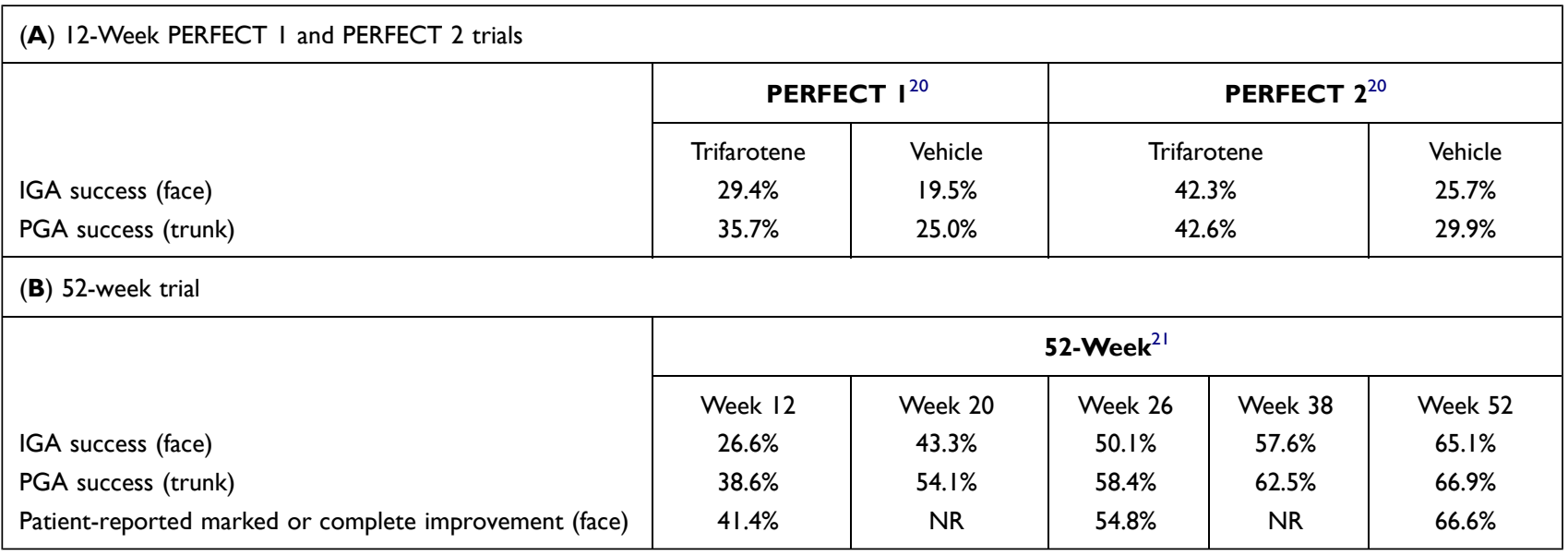

Abbreviations: IGA, Investigator Global Assessment; PGA, Physician Global Assessment. 
scaling, dryness, stinging/burning; Table 3). Overall, trifarotene was better tolerated on the trunk than on the face. Scores of local irritation peaked in severity at week 1 for the face and at weeks 2-4 for the trunk, after which scores decreased. In both trials combined, severe cutaneous AEs were experienced by 9 patients (skin irritation, sunburn, allergic dermatitis, and application site pain, erosion, or irritation); however, no AEs were considered serious. Adverse effects led to trifarotene discontinuation in $1.9 \%$ of patients in PERFECT 1 and $1.2 \%$ in PERFECT 2. No clinically significant changes were observed regarding vital signs, physical examinations, or laboratory measurements in either trial.

\section{2-Week Clinical Trial}

A 52-week, open-label, noncomparative trial was conducted concurrently with the PERFECT trials from 2015-2017 at multiple US and European sites. ${ }^{21}$ The primary objective of this study was to evaluate the longterm safety of trifarotene $50 \mu \mathrm{g} / \mathrm{g}$ in patients with acne vulgaris. Secondary aims included assessments of efficacy and quality of life (QoL). Eligibility criteria, safety assessments, and efficacy endpoints measured by investigators (IGA for the face and PGA for the trunk) paralleled the PERFECT trials. The study also included patient-reported evaluations of facial improvement from baseline on a 6-point scale (from $0=$ complete improvement to $6=$ worse). QoL was measured by the Dermatology Life Quality Index (DLQI) 30-point scale (higher score $=$ greater $\mathrm{QoL}$ impairment).

A total of 453 patients were enrolled and 348 patients completed the study. Demographics and baseline disease characteristics for all patients who initiated therapy are provided in Table 1.

Efficacy, as measured by IGA and PGA success rates, progressively increased throughout the study (Table 2B). Facial improvement (success rate by IGA) increased from $26.6 \%$ at week 12 , to $50.1 \%$ at week 26 , to $65.1 \%$ at week 52. Truncal improvements (success rate by PGA) were slightly higher: $38.6 \%$ at week $12,58.4 \%$ at week 26 , and $66.9 \%$ at week 52 . At week 52 , overall treatment success (IGA and PGA success in the same patient) was $57.9 \%$. Patient-reported improvement concerning facial acne followed the upward trends of investigator scores and even slightly exceeded them at all timepoints (Table 2B).

Table 3 Local Tolerability Data in Phase III Clinical Trials of Trifarotene in Acne Vulgaris

\begin{tabular}{|c|c|c|c|c|c|c|}
\hline & \multicolumn{3}{|c|}{ Face } & \multicolumn{3}{|c|}{ Trunk } \\
\hline & $\begin{array}{c}\text { PERFECT } \\
\mathbf{I}^{20}\end{array}$ & $\begin{array}{c}\text { PERFECT } \\
2^{20}\end{array}$ & $52-$ Week $^{21}$ & $\begin{array}{c}\text { PERFECT } \\
\mathbf{1}^{20}\end{array}$ & $\begin{array}{c}\text { PERFECT } \\
2^{20}\end{array}$ & 52-Week ${ }^{21}$ \\
\hline \multicolumn{7}{|l|}{ Erythema } \\
\hline $\mathrm{n}$ & NR & NR & 449 & NR & NR & 442 \\
\hline Mild (\%) & NR & NR & $46.8 \%$ & NR & $N R$ & $29.6 \%$ \\
\hline Moderate (\%) & $23.7 \%$ & $33.2 \%$ & $24.7 \%$ & $14.6 \%$ & $23.2 \%$ & $17.2 \%$ \\
\hline Severe (\%) & $2.5 \%$ & $10.0 \%$ & $2.2 \%$ & $3.3 \%$ & $7.2 \%$ & $5.4 \%$ \\
\hline \multicolumn{7}{|l|}{ Scaling } \\
\hline $\mathrm{n}$ & NR & NR & 449 & NR & NR & 442 \\
\hline Mild (\%) & $N R$ & $N R$ & $46.8 \%$ & $N R$ & $N R$ & $31.0 \%$ \\
\hline Moderate (\%) & $21.4 \%$ & $32.9 \%$ & $29.2 \%$ & $10.8 \%$ & $16.7 \%$ & $10.9 \%$ \\
\hline Severe (\%) & $2.9 \%$ & $6.8 \%$ & $2.2 \%$ & $0.3 \%$ & $3.0 \%$ & $2.5 \%$ \\
\hline \multicolumn{7}{|l|}{ Dryness } \\
\hline $\mathrm{n}$ & NR & NR & 449 & NR & NR & 442 \\
\hline Mild (\%) & $N R$ & NR & $43.4 \%$ & NR & $N R$ & $34.4 \%$ \\
\hline Moderate (\%) & $23.0 \%$ & $36.4 \%$ & $31.2 \%$ & $11.3 \%$ & $20.9 \%$ & $14.3 \%$ \\
\hline Severe (\%) & $2.5 \%$ & $7.1 \%$ & $5.8 \%$ & $1.2 \%$ & $2.5 \%$ & $2.7 \%$ \\
\hline \multicolumn{7}{|c|}{ Stinging/Burning } \\
\hline $\mathrm{n}$ & NR & NR & 449 & NR & $N R$ & 442 \\
\hline Mild (\%) & NR & NR & $37.6 \%$ & NR & NR & $25.1 \%$ \\
\hline Moderate (\%) & $16.3 \%$ & $24.9 \%$ & $21.2 \%$ & $9.0 \%$ & $12.9 \%$ & $9.5 \%$ \\
\hline Severe (\%) & $4.2 \%$ & $7.6 \%$ & $7.1 \%$ & $3.0 \%$ & $5.7 \%$ & $4.8 \%$ \\
\hline
\end{tabular}

Abbreviations: $n$, number; NR, not reported. 
Trifarotene was generally well tolerated. Local irritation was mostly mild, and moderate to severe irritation scores were within the ranges reported in the PERFECT studies (Table 3). Also similar to the PERFECT trials, facial irritation increased during week 1 and truncal irritation increased up to weeks $2-4$, then both subsequently decreased throughout the remainder of the study period. Overall, $12.6 \%$ of patients exhibited cutaneous AEs related to trifarotene (pruritus in $4.6 \%$, irritation in $4.2 \%$, sunburn in $1.8 \%$ ), which were mild and limited to application sites. Severe trifarotene-related AEs occurred in $0.3 \%$ (pruritus, erythema, and application site irritation). Adverse events related to trifarotene leading to treatment discontinuation occurred in $2.9 \%$ of patients and included skin irritation $(\mathrm{n}=10)$ and worsening of acne $(n=3)$. No clinically significant abnormalities in laboratory parameters were identified throughout the study. Upon study completion, $53.8 \%$ of patients reported acne had no effect on their QoL (DLQI score of 0 or 1), compared to $22.6 \%$ of patients at baseline.

\section{Ongoing and Future Studies}

The status of all completed and ongoing clinical trials to date studying the use of trifarotene in acne vulgaris are summarized in Table 4. There are two completed trials that

Table 4 All Completed and Upcoming Trials of Trifarotene in Acne Vulgaris

\begin{tabular}{|c|c|c|c|c|c|c|}
\hline Intervention & Study Design & $\begin{array}{c}\text { No. of } \\
\text { Patients }\end{array}$ & Location & Primary Endpoints & Status & Results \\
\hline Trifarotene $50 \mu \mathrm{g} / \mathrm{g}$ cream & $\begin{array}{l}\text { Interventional; } \\
\text { Phase III; single } \\
\text { group; open-label }\end{array}$ & 47 & US & $\begin{array}{l}\text { Success rate (IGA) score of } 0 \text { or I } \\
\text { or at least a } 2 \text {-grade improvement } \\
\text { from baseline to week } 12\end{array}$ & Completed & $\begin{array}{l}\text { Not yet } \\
\text { reported }^{22}\end{array}$ \\
\hline $\begin{array}{l}\text { Trifarotene } 50 \mu \mathrm{g} / \mathrm{g} \text { cream }+ \\
\text { I } 20 \mathrm{mg} \text { doxycycline hyclate; } \\
\text { trifarotene vehicle }+ \\
\text { doxycycline placebo }\end{array}$ & $\begin{array}{l}\text { Interventional; } \\
\text { Phase IV; } \\
\text { randomized; } \\
\text { parallel } \\
\text { assignment; } \\
\text { double-blind }\end{array}$ & 198 & $\begin{array}{l}\text { US \& Puerto } \\
\text { Rico }\end{array}$ & $\begin{array}{l}\text { Absolute change in facial total } \\
\text { lesion count from baseline to week } \\
\qquad 12\end{array}$ & Enrolling & $\begin{array}{l}\text { Not yet } \\
\text { reported }^{24}\end{array}$ \\
\hline $\begin{array}{l}\text { Trifarotene } 50 \mu g / g \text { cream; } \\
\text { trifarotene vehicle }\end{array}$ & $\begin{array}{l}\text { Interventional; } \\
\text { phase III; } \\
\text { randomized; } \\
\text { parallel } \\
\text { assignment; } \\
\text { quadruple-blind }\end{array}$ & 1208 & Multinational & $\begin{array}{l}\text { Success rate (IGA) score of } 0 \text { or I } \\
\text { or at least a } 2 \text {-grade improvement } \\
\text { from baseline to week } 12\end{array}$ & Completed & $\begin{array}{l}\text { Reported } \\
\text { in Tan } \\
\text { et } \mathrm{al}^{20}\end{array}$ \\
\hline $\begin{array}{l}\text { Trifarotene } 50 \mu g / g \text { cream; } \\
\text { trifarotene vehicle }\end{array}$ & $\begin{array}{l}\text { Interventional; } \\
\text { phase III; } \\
\text { randomized; } \\
\text { parallel } \\
\text { assignment; } \\
\text { quadruple-blind }\end{array}$ & 1212 & Multinational & $\begin{array}{c}\text { Success rate (IGA) score of } 0 \text { or I } \\
\text { or at least a } 2 \text {-grade improvement } \\
\text { from baseline to week } 12\end{array}$ & Completed & $\begin{array}{l}\text { Reported } \\
\text { in Tan } \\
\text { et } \text { al }^{20}\end{array}$ \\
\hline Trifarotene $50 \mu \mathrm{g} / \mathrm{g}$ cream & $\begin{array}{l}\text { Interventional; } \\
\text { phase III; single } \\
\text { group; open-label }\end{array}$ & 453 & Multinational & $\begin{array}{c}\text { Success rate (IGA) score of } 0 \text { or I } \\
\text { from baseline to week } 52\end{array}$ & Completed & $\begin{array}{l}\text { Reported } \\
\text { in Blume- } \\
\text { Peytavi } \\
\text { et } \text { al }^{21}\end{array}$ \\
\hline $\begin{array}{l}\text { Trifarotene } 25 \mu \mathrm{g} / \mathrm{g} \text { cream; } \\
\text { trifarotene } 50 \mu \mathrm{g} / \mathrm{g} \text { cream; } \\
\text { trifarotene } 100 \mu \mathrm{g} / \mathrm{g} \text { cream; } \\
\text { tazarotene } 0.1 \% \mathrm{gel} ; \\
\text { trifarotene vehicle }\end{array}$ & $\begin{array}{l}\text { Interventional; } \\
\text { Phase II; } \\
\text { randomized; } \\
\text { parallel } \\
\text { assignment; } \\
\text { quadruple-blind }\end{array}$ & 304 & US & $\begin{array}{l}\text { Success rate (IGA) score of } 0 \text { or } 1 \\
\text { or at least a 2-grade improvement } \\
\text { from baseline to week } 12 \text {; absolute } \\
\text { change in lesion count from } \\
\text { baseline to week } 12 \text {; percent } \\
\text { change in lesion count from } \\
\text { baseline to week } 12\end{array}$ & Completed & $\begin{array}{l}\text { Not yet } \\
\text { reported }^{23}\end{array}$ \\
\hline
\end{tabular}

Abbreviations: IGA, Investigator Global Assessment; PGA, Physician Global Assessment; US, United States. 
have not yet published or posted their results. The first study, "Subject reported outcomes with use of trifarotene $50 \mu \mathrm{g} / \mathrm{g}$ cream in the treatment of moderate facial and truncal acne vulgaris," was a Phase III, 12-week trial. ${ }^{22}$ The second study, "Dose range study of CD5789 in acne vulgaris," investigated the safety and efficacy of three doses of trifarotene $(25 \mu \mathrm{g} / \mathrm{g}, 50 \mu \mathrm{g} / \mathrm{g}$, and $100 \mu \mathrm{g} / \mathrm{g})$ for 12 weeks compared to tazarotene $0.1 \%$ gel and placebo. ${ }^{23}$

One upcoming Phase IV study, "A study to compare efficacy and safety of trifarotene cream when used with an oral antibiotic for the treatment of severe acne vulgaris (DUAL)," will investigate daily application of trifarotene $50 \mu \mathrm{g} / \mathrm{g}$ cream in combination with delayed release doxycycline $120 \mathrm{mg}^{24}$

\section{Use of Trifarotene in Clinical Practice and Future Directions}

One small, post-FDA-approval report discussing the realworld use of trifarotene in three patients with moderate acne has been published. ${ }^{25}$ The patients applied trifarotene $50 \mu \mathrm{g} / \mathrm{g}$ on the face and trunk for 12 weeks and were administered standardized questionnaires regarding treatment satisfaction. At 12 weeks, inflammatory lesions were reduced by $20-90 \%$ and noninflammatory lesions by $22-$ $47 \%$ among the three patients. Overall, patient satisfaction was high and two of three patients reported significant improvement in self-esteem. Despite the small number of patients, this study highlights the importance of patientreported outcomes, particularly regarding truncal acne, for which there is a scarcity of literature.

In the pivotal phase III clinical trials, trifarotene yielded highly favorable results with respect to safety, tolerability, and efficacy. As a selective activator of the skin-specific RAR-gamma, trifarotene may generate relatively less severe side effects of local irritation (such as those mediated by RAR-beta ${ }^{11}$ ) compared to the earlier generation retinoids that exhibit more nonselective RAR binding. To investigate this, head-to-head studies comparing the efficacy and tolerability of trifarotene with earlier generation retinoids are warranted and are already underway. Direct comparison studies may also validate the theorized superiority of RAR-gamma specificity that was evident in preclinical studies, which indicated trifarotene may exert better comedolytic and antipigmenting effects than other retinoids. Postinflammatory hyperpigmentation, which is more severe in skin of color, is a significant source of psychological distress in patients with acne. ${ }^{26}$
Given the implications from the initial animal study, future research should assess the impact of trifarotene on this particular complication of acne vulgaris.

All published studies to date have examined the use of trifarotene as monotherapy and in the single strength (50 $\mu \mathrm{g} / \mathrm{g})$ cream formulation. In clinical practice, acne treatment regimens commonly involve multiple concomitant therapies, thus the upcoming trial studying trifarotene in combination with oral doxycycline will help inform how to incorporate this novel medication into multi-agent treatment plans. Furthermore, studying varying trifarotene dosages will provide important data to guide future treatment approaches that are more specific to disease severity and tolerability. Given that other topical retinoids are available in both cream and gel formulations, future study of alternate formulations of trifarotene should be considered. For example, gel formulations are generally preferred in oily skin, a common phenotype in patients with acne, which presents a potential limitation for the use of trifarotene cream. ${ }^{27,28}$

The financial cost of trifarotene likely precludes its use in many patients. A 45-gram pump of trifarotene cream $0.005 \%$ costs approximately $\$ 575 .^{29}$ In contrast, a $45-$ gram tube of tretinoin cream $0.025 \%$ costs approximately $\$ 56,{ }^{30}$ and a 45 -gram tube of adapalene gel $0.1 \%$ costs approximately $\$ 35 .^{31}$ Uninsured patients and those with commercial insurance may participate in a discount program offered by the manufacturer of trifarotene, allowing purchase of a 45 -gram pump of trifarotene $0.005 \%$ for $\$ 75$ and $\$ 0$, respectively. ${ }^{32}$ Another potential barrier to widespread usage is that trifarotene is available by prescription only, in contrast to adapalene $0.1 \%$ gel which may be purchased over the counter. ${ }^{16}$

Limitations of this review include the small number of available articles regarding the use of trifarotene in clinical practice. The majority of clinical data discussed here pertain to two articles describing three large clinical trials. ${ }^{20,21}$ Given the recent entry of trifarotene into the market, there are very few post-approval studies published in the literature.

\section{Conclusion}

Acne vulgaris is a common cutaneous condition that negatively impacts QoL and self-esteem. Trifarotene is a firstin-class fourth-generation topical retinoid approved by the FDA for the treatment of acne vulgaris in patients $\geq 9$ years of age. It is the first topical retinoid to be specifically studied in both facial and truncal acne. In clinical studies, trifarotene $50 \mu \mathrm{g} / \mathrm{g}$ cream yielded favorable safety, 
tolerability, and efficacy data in patients with moderate acne. Continuous improvement over time was observed according to both investigator and patient assessments in long-term study. Trifarotene exhibits high selectivity for the skin-predominant RAR-gamma, thus theoretically rendering a superior local tolerability profile than the earlier generation retinoids, which bind more nonselectively to the different RAR subtypes. Direct comparison studies will investigate this hypothesis, as well as provide data regarding the efficacy of trifarotene relative to other topical retinoids.

\section{Abbreviations}

AE, adverse event; ATRA, all-trans retinoic acid; Cmax, maximum concentration; DLQI, Dermatology Life Quality Index; EE, ethinyl estradiol; FDA, Food and Drug Administration; IGA, Investigator Global Assessment; LNG, levonorgestrel; PGA, Physician Global Assessment; QoL, quality of life; RAR, retinoic acid receptor; RARE, retinoic acid receptor response element; $\mathrm{RXR}$, retinoic $\mathrm{X}$ receptor.

\section{Disclosure}

The authors declare that they have no conflict of interest and no financial disclosure.

\section{References}

1. Vos T, Flaxman AD, Naghavi M, et al. Years lived with disability (YLDs) for 1160 sequelae of 289 diseases and injuries 1990-2010: a systematic analysis for the Global Burden of Disease Study 2010. Lancet. 2012;380(9859):2163-2196. doi:10.1016/S0140-6736(12) 61729-2

2. Collier CN, Harper JC, Cafardi JA, et al. The prevalence of acne in adults 20 years and older. $J$ Am Acad Dermatol. 2008;58(1):56-59. doi:10.1016/j.jaad.2007.06.045

3. Tan JK, Bhate K. A global perspective on the epidemiology of acne. Br J Dermatol. 2015;172(Suppl 1):3-12. doi:10.1111/bjd.13462

4. Misery L. Consequences of psychological distress in adolescents with acne. J Invest Dermatol. 2011;131(2):290-292. doi:10.1038/ jid. 2010.375

5. Singam V, Rastogi S, Patel KR, Lee HH, Silverberg JI. The mental health burden in acne vulgaris and rosacea: an analysis of the US national inpatient sample. Clin Exp Dermatol. 2019;44(7):766-772. doi:10.1111/ced.13919

6. Halvorsen JA, Stern RS, Dalgard F, Thoresen M, Bjertness E, Lien L. Suicidal ideation, mental health problems, and social impairment are increased in adolescents with acne: a Population-Based Study. J Invest Dermatol. 2011;131(2):363-370. doi:10.1038/jid.2010.264

7. O'Neill AM, Gallo RL. Host-microbiome interactions and recent progress into understanding the biology of acne vulgaris. Microbiome. 2018;6(1):177. doi:10.1186/s40168-018-0558-5

8. Di Landro A, Cazzaniga S, Parazzini F, et al. Family history, body mass index, selected dietary factors, menstrual history, and risk of moderate to severe acne in adolescents and young adults. $J$ Am Acad Dermatol. 2012;67(6):1129-1135. doi:10.1016/j.jaad.2012.02.018
9. Zaenglein AL, Pathy AL, Schlosser BJ, et al. Guidelines of care for the management of acne vulgaris. J Am Acad Dermatol. 2016;74 (5):945-973e 933 .

10. Williams HC, Dellavalle RP, Garner S. Acne vulgaris. Lancet. 2012;379(9813):361-372. doi:10.1016/S0140-6736(11)60321-8

11. Balak DMW. Topical trifarotene: a new retinoid. Br J Dermatol. 2018;179(2):231-232.

12. Kolli SS, Pecone D, Pona A, Cline A, Feldman SR. Topical retinoids in acne vulgaris: a systematic review. Am J Clin Dermatol. 2019;20 (3):345-365. doi:10.1007/s40257-019-00423-z

13. Thoreau E, Arlabosse JM, Bouix-Peter C, et al. Structure-based design of trifarotene (CD5789), a potent and selective RARgamma agonist for the treatment of acne. Bioorg Med Chem Lett. 2018;28 (10):1736-1741. doi:10.1016/j.bmcl.2018.04.036

14. Galderma. Aklief (trifarotene). US Food and Drug Administration. Available from: https://www.accessdata.fda.gov/drugsatfda_docs/ label/2019/211527s000lbl.pdf. Accessed April 17, 2021.

15. Aubert J, Piwnica D, Bertino B, et al. Nonclinical and human pharmacology of the potent and selective topical retinoic acid receptor-gamma agonist trifarotene. Br J Dermatol. 2018;179 (2):442-456. doi:10.1111/bjd.16719

16. Chien A. Retinoids in acne management: review of current understanding, future considerations, and focus on topical treatments. J Drugs Dermatol. 2018;17(12):s51-55.

17. Mukherjee S, Date A, Patravale V, Korting HC, Roeder A, Weindl G. Retinoids in the treatment of skin aging: an overview of clinical efficacy and safety. Clin Interv Aging. 2006;1(4):327-348. doi:10.2147/ciia.2006.1.4.327

18. Wagner N, Benkali K, Alio Saenz A, Poncet M, Graeber M. Clinical pharmacology and safety of trifarotene, a first-in-class rargamma-selective topical retinoid. J Clin Pharmacol. 2020. doi: $10.1002 / \mathrm{jcph} .1566$

19. Rosa FW. Teratogenicity of isotretinoin. Lancet. 1983;2(8348):513. doi:10.1016/S0140-6736(83)90538-X

20. Tan J, Thiboutot D, Popp G, et al. Randomized Phase 3 evaluation of trifarotene $50 \mathrm{mug} / \mathrm{g}$ cream treatment of moderate facial and truncal acne. J Am Acad Dermatol. 2019;80(6):1691-1699. doi:10.1016/j. jaad.2019.02.044

21. Blume-Peytavi U, Fowler J, Kemeny L, et al. Long-term safety and efficacy of trifarotene $50 \mathrm{mug} / \mathrm{g}$ cream, a first-in-class RAR-gamma selective topical retinoid, in patients with moderate facial and truncal acne. J Eur Acad Dermatol Venereol. 2020;34(1):166-173. doi: $10.1111 / j \mathrm{dv} .15794$

22. Clinicaltrials.gov. Subject reported outcomes with use of trifarotene $50 \mu \mathrm{g} / \mathrm{g}$ cream in the treatment of moderate facial and truncal acne vulgaris. Available from: https://clinicaltrials.gov/ct2/show/ NCT03915860? term $=$ trifarotene $\&$ cond $=$ Acne + Vulgaris \&draw $=$ 2\&rank=1. Accessed April 28, 2021.

23. Clinicaltrials.gov. Dose Range Study of CD5789 in acne vulgaris. Available from: https://clinicaltrials.gov/ct2/show/NCT01616654? term $=$ trifarotene $\&$ cond $=A c n e+$ Vulgaris $\&$ draw $=2 \&$ rank $=7$. Accessed April 28, 2021.

24. Clinicaltrials.gov. A study to compare efficacy and safety of trifarotene cream when used with an oral antibiotic for the treatment of severe acne vulgaris (AV) (DUAL). Available from: https:/clinical trials.gov/ct $2 /$ show/NCT04451330? term $=$ trifarotene\&cond=Acne +Vulgaris\&draw=2\&rank=5. Accessed April 28, 2021.

25. Johnson SM, Chavda R, DuBois JC. Subject satisfaction with trifarotene $50 \mathrm{mug} / \mathrm{g}$ cream in the treatment of facial and truncal acne vulgaris: a case series. Dermatol Ther (Heidelb). 2020;10 (5):1165-1173. doi:10.1007/s13555-020-00417-4

26. Kaufman BP, Aman T, Alexis AF. Postinflammatory hyperpigmentation: epidemiology, clinical presentation, pathogenesis and treatment. Am J Clin Dermatol. 2018;19(4):489-503. doi:10.1007/s40257-0170333-6 
27. Latter G, Grice JE, Mohammed Y, Roberts MS, Benson HAE Targeted topical delivery of retinoids in the management of acne vulgaris: current formulations and novel delivery systems. Pharmaceutics. 2019;11(10):490. doi:10.3390/ pharmaceutics 11100490

28. Bell KA, Brumfiel CM, Haidari W, Boger L. Trifarotene for the treatment of facial and truncal acne. Ann Pharmacother. 2021;55 (1):111-116. doi:10.1177/1060028020934892

29. GoodRx. Aklief. Available from: https:/www.goodrx.com/aklief? dosage $=45 \mathrm{~g}$-of- $0.005 \% 25 \&$ form $=$ cream-pump $\&$ label_override =Aklief\&quantity=1\&sort_type=popularity. Accessed April 17, 2021.
30. GoodRx. Tretinoin. Available from: https://www.goodrx.com/treti noin? dosage $=45 \mathrm{~g}$-of $-0.025 \% 25 \&$ form $=$ tube-of-

cream\&label_override $=$ tretinoin $\&$ quantity $=1 \&$ sort_type $=$ popularity. Accessed April 17, 2021.

31. GoodRx. Adapalene. Available from: https://www.goodrx.com/dif ferin?dosage $=45 \mathrm{~g}$-of- $0.1 \% 25 \&$ form $=$ tube-of-gel\&label_override $=$ ada palene\&quantity=1\&sort_type=popularity. Accessed April 17, 2021.

32. Galderma. Aklief savings. Available from: https://aklief.com/savings. Accessed April 17, 2021.

\section{Publish your work in this journal}

Therapeutics and Clinical Risk Management is an international, peerreviewed journal of clinical therapeutics and risk management, focusing on concise rapid reporting of clinical studies in all therapeutic areas, outcomes, safety, and programs for the effective, safe, and sustained use of medicines. This journal is indexed on PubMed Central, CAS,
EMBase, Scopus and the Elsevier Bibliographic databases. The manuscript management system is completely online and includes a very quick and fair peer-review system, which is all easy to use. Visit http://www.dovepress.com/testimonials.php to read real quotes from published authors. 